\title{
The Influence of Age on Body Structure and Body Compositionof Patients Undergoing Chronic Peritoneal Dialysis, And Its Relationship with The Treatment Schedules
}

\author{
Giancarlo Ruggieri
}

\begin{abstract}
This paper studied the possible influence of age on the physical conditions and, with a secondary interest, of the dialytic treatment, of a population of 17 males and 32 females undergoing peritoneal dialysis. The influence of age was studied comparing the conditions of the patients separated in groups of different age, the first group based for males and females on the average age, the second group on the age greater and lower 60 years and the third group on the age greater and lower 67 years, this to ascertain if the progressive aging could induce different effects. The result of this research, possibly limited by an insufficient numerousness of the studied populations, showed that very probably the results obtained separating the bodily structures according to the greater and lower average age were modified with the increasing of age to 60 years and 67 years, these last groups significantly decreasing the differences between the bodily properties, when separating greater and lower age, respect to the similar separation operated in average age : that is to say that the aging beyond the basal age of the studied populations (males $\mathbf{5 8 . 8} \pm \mathbf{1 6 . 3 8}$,females $\mathbf{5 5 . 1} \pm \mathbf{1 0 . 5 2}$ ) decreases the possible differences existing in bodily properties. For what concerning the dialytic treatment,a significant difference was pointed out for males and for females about the average age, but for what concerning the differences greater versus lower of 60 years and 67 years, not significant differences resulted for males, which differently resulted for females.

Index Terms - age, body structure.
\end{abstract}

\section{INTRODUCTION}

Premise - The increasing of age is naturally tied to a worsening of body structure, even strongly influenced by the degrees of care that the single person will give to his/her maintenance, this not only in terms of the physic conditions but also for what concerning the intellectual conditions, having attention to exercise the brain activity. The beneficial effects of all these cares may be heavy decreased in case of the coexistence of debilitating physic defects, or in case of condition of a chronic disease able to modify in depth the conditions of life of the persons. Based on the previous considerations, it seemed it could be of interest to study the influence of age in a population represented by 17 males and 32 females, affected by a terminal renal disease and for this undergoing to a dialytic treatment by chronic peritoneal dialysis. Their age was respectively for males $58.8 \pm 16.38$ and for females 55.1 \pm 10.52 , a not significant difference, $\mathrm{T}$ value $=0.84, \mathrm{p}=0.408$.

Giancarlo Ruggieri, Past affiliation: San Giacomo and ONRM Hospitals, Department of Nephrology and Urology, Roma, Italy

\section{METHOD}

The data concerning the populations of 17 males and 32 females was separated in two groups, the first considering all the data selected on base of the age greater the mean of age and the second concerning the data selected on base of age lower the mean of age. The used data are reported as it follows : resistance, resistance/BMI, reactance, reactance/BMI, height, weight, BMI, BSA DuBois, fat mass $\mathrm{i} \%$, fat mass $\mathrm{kgs}$, extracellular water $\%$, extracellular water $\mathrm{kgs}$, cellular mass \%, cellular mass\%/BMI, cellular mass kgs, cellular mass $\mathrm{kgs} / \mathrm{BMI}, \quad$ creatininemia, creatininemia/BMI,BUN,BUN/BMI, total protidemia, total protidemia/BMI, albuminemia, albuminemia/BMI, cholesterolemia, triglycerides, triglycerides/BMI, $\mathrm{Hb}$, $\mathrm{Hb} / \mathrm{BMI}$, hematocrit, hematocrit/BMI, transferrine, transferrine/BMI, lymphocytes, lynphocythes/BMI,C3, C3/BMI, IgG, IgG/BMI, dialyzed volume, dialyzed volume/BMI. 
The Influence of Age on Body Structure and Body Compositionof Patients Undergoing Chronic Peritoneal Dialysis, And Its Relationship with The Treatment Schedules

The results of the separation are reported for males in Table I, II,V,VI,IX,X, and for females, in Tables III,IV,IVA, VII,VIII,X,XII.

\begin{tabular}{|c|c|c|c|c|c|c|c|c|}
\hline & \multirow{2}{*}{ Variables } & \multicolumn{2}{|c|}{ data by greater age } & \multicolumn{2}{|c|}{$\begin{array}{l}\text { data by lower } \\
\text { age }\end{array}$} & \multicolumn{2}{|c|}{ statistics } & \multirow{2}{*}{$\begin{array}{l}\text { scores } \\
5\end{array}$} \\
\hline 1 & & 67.83 & 6.53 & $37 ., 2$ & 11.3 & 5.68 & 0.002 & \\
\hline 2 & Height & 163.3 & 4.87 & 178.6 & 4.67 & -6.08 & 0.001 & 5 \\
\hline 3 & $\mathrm{FMi} \%$ & 24.27 & 6.08 & $17 . .1$ & 4.46 & 2,7 & 0.022 & 3 \\
\hline 4 & FM kg & 18.2 & 6.81 & 12.46 & 2.59 & 2.52 & 0.025 & 3 \\
\hline 5 & $\begin{array}{l}\text { Extracellular } \quad \text { water } \\
\mathrm{kgs} / \mathrm{BMI}\end{array}$ & 1,154 & 0.13 & 1.4 & 0.067 & -5.12 & 0.000 & 7 \\
\hline 6 & Cellular mass \%/BMI & 1.31 & 0.26 & 1.79 & 0.37 & -2.64 & 0.046 & 3 \\
\hline 7 & Cellular mass kgs/BMI & 0.94 & 0.101 & 1.3 & 0.13 & -5.54 & 0.001 & 5 \\
\hline 8 & Creatininemia/BMI & 0,38 & 0.076 & 0.513 & 0.094 & -2.8 & 0.031 & 3 \\
\hline 9 & Cholesterolemia & 233.1 & 35.6 & 184.8 & 26.47 & 3.08 & 0,012 & 3 \\
\hline $0^{1}$ & $\mathrm{C} 3$ & 95 & 19.8 & 77.72 & 7.58 & 2.6 & 0.021 & 3 \\
\hline \begin{tabular}{l|}
1 \\
1
\end{tabular} & dialyzed V/BMI & 459.8 & 244.47 & 624.4 & 328.8 & -37.8 & 0.000 & 7 \\
\hline & & & & & & & mean & 4.27 \\
\hline & & & & & & & SD & 1.62 \\
\hline
\end{tabular}

\begin{tabular}{|c|c|c|c|c|c|c|c|}
\hline \multicolumn{8}{|c|}{ Variables } \\
\hline 1 & Resistance & 12 & BMI & 22 & Triglycerides & $2^{3}$ & $\mathrm{C} 3 / \mathrm{BMI}$ \\
\hline 2 & Resistance/BMI & 13 & BSA DuBois & 23 & Triglycerides/BMI & $3^{3}$ & $\mathrm{IgG}$ \\
\hline 3 & Reactance & 14 & FM kg/BMI & 24 & $\mathrm{Hb}$ & $4^{3}$ & $\mathrm{I}^{\mathrm{IgG} / \mathrm{BM}}$ \\
\hline 4 & Reactance/BMI & 15 & Extracellular water \% & 25 & $\mathrm{Hb} / \mathrm{BMI}$ & $5^{3}$ & $\mathrm{~V}^{\text {dialyzed }}$ \\
\hline 6 & Weight & 16 & $\begin{array}{l}\text { Extracellular water } \\
\text { kgs }\end{array}$ & 26 & Hematocrit & & \\
\hline 7 & Cellular mass $\%$ & 17 & Total protidemia & 27 & Hematocrit/BMI & & \\
\hline 8 & $\begin{array}{l}\text { Cellular mass } \\
\mathrm{kgs}\end{array}$ & 18 & Total protidemia/BMI & 28 & Transferrine & & \\
\hline 9 & Creatininemia & 19 & Albuminemia & 29 & Transferrine/BMI & & \\
\hline 0 & BUN & 20 & Albuminemia/BMI & 30 & Lynphocythes & & \\
\hline 1 & BUN/BMI & 21 & Cholesterolemia/BMI & 31 & $\begin{array}{l}\text { Lynphocythes/BM } \\
\text { I }\end{array}$ & & \\
\hline
\end{tabular}

Table III - Females - Variables separated according to average age (55,1 years) resulting with significant differences

\begin{tabular}{|l|l|c|c|c|c|c|c|c|}
\hline & variables & \multicolumn{2}{|c|}{$\begin{array}{c}\text { data by greater } \\
\text { age }\end{array}$} & mean & SD & mean & SD & \multicolumn{2}{l|}{ T value } & p & scores \\
\hline order & variables & 65.55 & 5.89 & 49.62 & 7.91 & 6.43 & 0.000 & 7 \\
\hline 1 & Age & 8628 & 993 & 15157 & 7128 & -4.12 & 0.000 & 7 \\
\hline 2 & Dialyzed V & 349.6 & 61.14 & 592 & 289.6 & -3.68 & 0.001 & 5 \\
\hline 3 & Dialyzed V/BMI & & & mean & 6.33 \\
\hline
\end{tabular}


Table IV - Females - Variables separated according to average age (55,1years) resulting without significant differences Variables

\begin{tabular}{|l|l|l|l|}
\hline 1 & Resistance & 11 & FM kg/BMI \\
\hline 2 & Resistance/BMI & 12 & Extracellular water kgs \\
\hline 3 & Reactance & 13 & Extracellular water kgs/BMI \\
\hline 4 & Reactance/BMI & 14 & cellular mass $\%$ \\
\hline 5 & Height & 15 & cellular mass \%/BMI \\
\hline 6 & Weight & 16 & cellular mass kgs \\
\hline 7 & BMI & 17 & cellular mass kgs/BMI \\
\hline 8 & BSA DuBois & 18 & Creatininemia \\
\hline 9 & FMi\% & 19 & Creatininemia/BMI \\
\hline 10 & FM Kg & 20 & BUN \\
\hline
\end{tabular}

Table IV A - Females - Variables separated according to average age (55,1years) resulting without significant differences Variables

\begin{tabular}{|l|l|l|l|}
\hline 11 & BUN/BMI & 22 & Hematocrit \\
\hline 12 & total protidemia & 23 & hematocrit/BMI \\
\hline 13 & total protidemia/BMI & 24 & Transferrine \\
\hline 14 & Albuminemia & 25 & Transferrine/BMI \\
\hline 15 & Albuminemia/BMI & 26 & Lynphocythes \\
\hline 16 & Cholesterol & 27 & Lynphocythes/BMI \\
\hline 17 & Cholesterolemia/BMI & 28 & C3 \\
\hline 18 & Triglycerides & 29 & C3/BMI \\
\hline 19 & Triglycerides/BMI & 30 & IgG \\
\hline 20 & Hb & 31 & IgG/BMI \\
\hline 21 & Hb/BMI & & \\
\hline
\end{tabular}

Further evaluations were elaborated for males and females, concerning the possible differences between greater and lower data, based on separations between an age greater and lower 60 years and greater and lower 67 years, whose data are reported in the following Tables

Table V - Males - Variables separated according to age greater and lower 60 years resulting with significant differences

\begin{tabular}{|c|c|c|c|c|c|c|c|c|}
\hline \multirow{2}{*}{$\begin{array}{l}\text { order } \\
1 \\
\end{array}$} & \multirow{2}{*}{$\begin{array}{l}\text { variables } \\
\text { Reactance/BMI }\end{array}$} & \multicolumn{2}{|c|}{ data by greater age } & \multicolumn{2}{|c|}{ data by lower age } & \multicolumn{2}{|c|}{ statistics } & \multirow{2}{*}{$\begin{array}{l}\text { Scores } \\
3 \\
\end{array}$} \\
\hline & & 1.54 & 0.3 & 2.35 & 0.78 & -2.76 & 0.025 & \\
\hline 2 & Age & 70.78 & 4.44 & 45.4 & 14.15 & 4.86 & 0.001 & 5 \\
\hline 3 & Height & 162.9 & 5.11 & 173.4 & 8.42 & -3.06 & 0.011 & 3 \\
\hline 4 & BMI & 29 & 3.59 & 23.3 & 3.86 & 3,14 & 0.007 & 5 \\
\hline 5 & FMi\% & 25.2 & 6.22 & 18.72 & 5.06 & 2.37 & 0.033 & 3 \\
\hline 6 & FM kg & 19.8 & 7.06 & 12.8 & 2.58 & 2.47 & 0.036 & 3 \\
\hline 7 & Extracellular water kgs/BMI & 1.15 & 0.12 & 1.31 & 0.16 & -2.31 & 0.04 & 3 \\
\hline 10 & Creatininemia/BMI & 0.348 & 0.049 & 0.5 & 0.077 & -4.79 & 0.001 & 5 \\
\hline 11 & Total protidemia/BMI & 0.248 & 0.027 & 0.306 & 0.06 & -2.52 & 0.033 & 3 \\
\hline 12 & Albuminemia/BMI & 0.133 & 0.02 & 0.18 & 0.04 & -3.01 & 0.013 & 3 \\
\hline 13 & $\mathrm{Hb} / \mathrm{BMI}$ & 0.326 & 0.065 & 0.44 & 0.107 & -2.61 & 0.024 & 3 \\
\hline
\end{tabular}

Table V - Males - Variables separated according to age greater and lower 60 years resulting with significant differences - following data

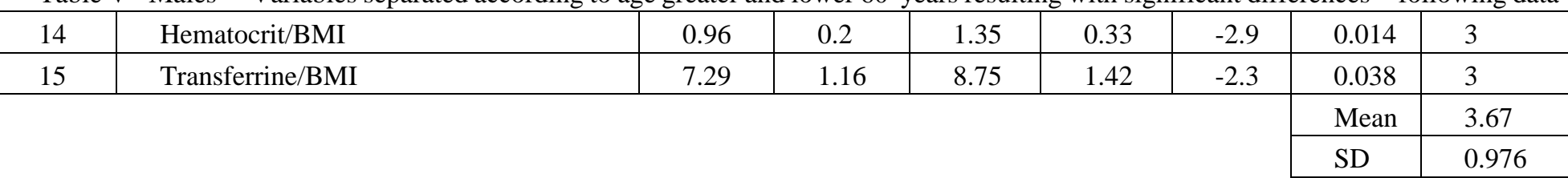


The Influence of Age on Body Structure and Body Compositionof Patients Undergoing Chronic Peritoneal Dialysis, And Its Relationship with The Treatment Schedules

\begin{tabular}{|l|l|r|l|l|l|}
\hline \multicolumn{6}{|c|}{ Table VI- Males - Variables separated according to age greater and lower 60 years resulting without significant differences } \\
\hline order & variables & $\begin{array}{c}\text { ord } \\
\text { er }\end{array}$ & $\begin{array}{l}\text { variables } \\
\text { order }\end{array}$ & Variables \\
\hline 1 & Resistance & 11 & Creatininemia & 21 & Transferrine \\
\hline 2 & Resistance/BMI & 12 & BUN & 22 & Lynphocythes \\
\hline 3 & Reactance & 14 & BUN/BMI & 23 & Lynphocythes/BMI \\
\hline 4 & Weight & 15 & Cholesterolemia & 25 & C3/BMI \\
\hline 5 & BSA DuBois & 16 & Cholesterolemia/BMI & 26 & IgG \\
\hline 6 & FM kg/BMI & 17 & Triglycerides & 27 & IgG/BMI \\
\hline 7 & Extracellular water $\%$ & 18 & Triglycerides/BMI & 28 & dialyzed V \\
\hline 8 & Extracellular water kgs & 19 & Hb & 29 & dialyzed V/BMI \\
\hline 9 & Cellular mass $\%$ & 20 & hematocrit & & \\
\hline 10 & Cellular mass kgs & & & \\
\hline
\end{tabular}

\begin{tabular}{|c|l|l|l|l|l|l|l|c|}
\hline \multicolumn{8}{|c|}{ Table VII - Females - Variables separated according to age greater lower 60 years resulting with significant differences } \\
\hline \multirow{2}{*}{ order } & variables & mean & SD & Mean & SD & T value & p & $\begin{array}{c}\text { scor } \\
\text { es }\end{array}$ \\
\hline 1 & Age & 67.22 & 8.09 & 50.35 & 7.92 & 5.33 & 0.000 & 7 \\
\hline 2 & Extracellular water \% & 41.56 & 3.91 & 46.13 & 7.15 & -2.31 & 0.029 & 3 \\
\hline 3 & Extracellular water kgs & 24.6 & 3.88 & 29.32 & 5.94 & -2.64 & 0.015 & 3 \\
\hline 4 & Dialyzed volume & 8790 & 805 & 14526 & 7122 & -3.8 & 0.001 & 5 \\
\hline 5 & Dialyzed volume/BMI & 355.8 & 65.32 & 568.7 & 287.07 & -3.34 & 0.003 & 5 \\
\hline & & & & & Mean & 4.6 \\
\cline { 5 - 8 } &
\end{tabular}

Table VIII - Females - Variables separated according to age greater lower 60 years resulting without significant differences

\begin{tabular}{|c|c|c|c|c|c|c|c|}
\hline order & Variables & order & Variables & order & Variables & order & Variables \\
\hline 1 & Height & 11 & Cellular mass kgs & 21 & Cholesterolemia & 31 & Lynphocythes \\
\hline 2 & Weight & 12 & $\begin{array}{l}\text { Cellular mass } \\
\mathrm{kgs} / \mathrm{BMI}\end{array}$ & 22 & $\begin{array}{l}\text { Cholesterolemia/B } \\
\text { MI }\end{array}$ & 32 & $\begin{array}{l}\text { Lynphocythes/B } \\
\text { MI }\end{array}$ \\
\hline 3 & BMI & 13 & Creatininemia & 23 & Triglycerides & 33 & $\mathrm{C} 3$ \\
\hline 4 & BSA DuBois & 14 & Creatininemia/BMI & 24 & Triglycerides/BMI & 34 & C3/BMI \\
\hline 5 & FMi $\%$ & 15 & BUN & 25 & $\mathrm{Hb}$ & 35 & IgG \\
\hline 6 & FM kg & 16 & BUN/BMI & 26 & $\mathrm{Hb} / \mathrm{BMI}$ & 36 & IgG/BMI \\
\hline 7 & $\mathrm{FM} \mathrm{kg/BMI}$ & 17 & Total protidemia & 27 & Hematocrit & & \\
\hline 8 & $\begin{array}{l}\text { Extracellular water } \\
\mathrm{kgs} / \mathrm{BMI}\end{array}$ & 18 & Total protidemia/BMI & 28 & Hematocrit/BMI & & \\
\hline 9 & Cellular mass $\%$ & 19 & Albuminemia & 29 & Transferrine & & \\
\hline 10 & Cellular mass \%/BMI & 20 & Albuminemia/BMI & 30 & Transferrine/BMI & & \\
\hline
\end{tabular}

Table IX - Males - Variables separated according to age greater and lower 67 years resulting with significant differences

\begin{tabular}{|c|c|c|c|c|c|c|c|c|}
\hline order & variables & $\begin{array}{l}\text { data b } \\
\text { age }\end{array}$ & greater & $\begin{array}{l}\text { data } \\
\text { age }\end{array}$ & y lower & $\mathrm{T}$ value & $\mathrm{P}$ & scores \\
\hline 1 & Age & 72.7 & 2.5 & 49.1 & 14.7 & 4.98 & 0.001 & 5 \\
\hline 2 & Height & 162.3 & 5.5 & $7^{171 .}$ & 8.34 & -2.8 & 0.014 & 3 \\
\hline 3 & cellular mass kgs/BMI & 0.92 & 0.06 & 1.14 & 0.22 & -3.01 & 0.013 & 3 \\
\hline 4 & Creatininemia/BMI & 0.35 & 0.06 & 0.47 & 0.1 & -3.08 & 0.008 & 5 \\
\hline 5 & Albuminemia/BMI & 0.135 & 0.02 & 0.17 & 0.043 & -2.25 & 0.042 & 3 \\
\hline
\end{tabular}


World Journal of Research and Review (WJRR)

ISSN:2455-3956, Volume-8, Issue-6, June 2019 Pages 16-23

\begin{tabular}{|l|l|l|l|l|l|l|l|l|}
6 & hematocrit/BMI & 0.97 & 0.22 & 1.27 & 0.34 & -2.21 & 0.044 & 3 \\
\hline 7 & Transferrine/BMI & 7.08 & 1.22 & 8.61 & 1.31 & -2.47 & 0.028 & 3 \\
\hline
\end{tabular}

Table X - Males - Variables separated according to age greater and lower 67 years resulting without significant differences

\begin{tabular}{|c|c|c|c|c|c|c|c|}
\hline $\begin{array}{l}\text { or } \\
\text { der }\end{array}$ & Variables & order & Variables & order & Variables & order & Variables \\
\hline 1 & Resistance & 11 & Extracellular water \% & 21 & $\begin{array}{l}\text { Total } \\
\text { protidemia/BMI }\end{array}$ & 31 & Lynphocythes \\
\hline 2 & $\begin{array}{l}\text { Resistance/B } \\
\text { MI }\end{array}$ & 12 & Extracellular water kgs & 22 & Albuminemia & 32 & Lynphocythes/BMI \\
\hline 3 & Reactance & 13 & $\begin{array}{l}\text { Extracellular water } \\
\mathrm{kgs} / \mathrm{BMI}\end{array}$ & 23 & Cholesterolemia & 33 & $\mathrm{C} 3$ \\
\hline 4 & $\begin{array}{l}\text { Reactance/B } \\
\text { MI }\end{array}$ & 14 & Cellular mass $\%$ & 24 & $\begin{array}{l}\text { Cholesterolemia/B } \\
\text { MI }\end{array}$ & 34 & $\mathrm{C} 3 / \mathrm{BMI}$ \\
\hline 5 & Weight & 15 & Cellular mass \%/BMI & 25 & Triglycerides & 35 & IgG \\
\hline 6 & BMI & 16 & Cellular mass kgs & 26 & Triglycerides/BMI & 36 & $\mathrm{IgG/BMI}$ \\
\hline 7 & BSA DuBois & 17 & Creatininemia & 27 & $\mathrm{Hb}$ & 37 & Dialyzed volume \\
\hline 8 & FMi\% & 18 & BUN & 28 & $\mathrm{Hb} / \mathrm{BMI}$ & 38 & $\begin{array}{c}\text { Dialyzed } \\
\text { volume/BMI }\end{array}$ \\
\hline 9 & FM kg & 19 & BUN/BMI & 29 & Hematocrit & & \\
\hline 10 & FM kg/BMI & 20 & Total protidemia & 30 & Transferrine & & \\
\hline
\end{tabular}

Table XI - Females - Variables separated according to age greater and lower 67 years resulting with significant differences

\begin{tabular}{|c|l|c|c|c|c|c|c|c|}
\hline $\begin{array}{c}\text { ord } \\
\text { er }\end{array}$ & variables & \multicolumn{2}{|c|}{ data by greater age } & data by lower age & T value & $\mathrm{p}$ & Scores \\
\hline 1 & reactance & 59.7 & 3.51 & 52.5 & 11.7 & 2.49 & 0.042 & 3 \\
\hline 2 & Reactance/BMI & 2.5 & 0.205 & 2.08 & 0.61 & 2.62 & 0.039 & 3 \\
\hline 3 & age & 73.67 & 0.58 & 52.68 & 8.79 & 13.21 & 0.000 & 7 \\
\hline 4 & Extracellular water \% & 40.33 & 1,53 & 45.36 & 6.96 & -3.32 & 0.006 & 5 \\
\hline 5 & Extracellular water \% & 40.33 & 1.53 & 45.36 & 6.96 & -3.32 & 0.006 & 5 \\
\hline & Cellular mass kgs/BMI & 0.901 & 0.053 & 0.789 & 9 & -3.32 & 0.006 & 5 \\
\hline 7 & Dialyzed volume & 8503 & 1526 & 13518 & 6795 & -3.37 & 0.005 & 5 \\
\hline & Dialyzed volume/BMI & 353.7 & 42.76 & 530.6 & 2 & -3.225 & 0.003 & 5 \\
\hline 8 & & & & & & & \\
\end{tabular}

\begin{tabular}{|c|c|c|c|c|c|}
\hline \multicolumn{6}{|c|}{$\begin{array}{l}\text { Table XII - Females - Variables separated according to age greater and lower } 67 \text { years resulting } \\
\text { without significant differences }\end{array}$} \\
\hline or & Variables & $\begin{array}{c}\text { or } \\
\text { der }\end{array}$ & Variables & $\begin{array}{l}\text { or } \\
\text { der }\end{array}$ & Variables \\
\hline 1 & Height & 13 & Creatininemia & 25 & $\mathrm{Hb}$ \\
\hline 2 & Weight & 14 & Creatininemia/BMI & 26 & $\mathrm{Hb} / \mathrm{BMI}$ \\
\hline 3 & BMI & 15 & BUN & 27 & hematocrit \\
\hline 4 & BSA DuBois & 16 & BUN/BMI & 28 & hematocrit/BMI \\
\hline 5 & FMi\% & 17 & Total protidemia & 29 & Transferrine \\
\hline 6 & FM kg & 18 & $\begin{array}{l}\text { Total } \\
\text { protidemia/BMI }\end{array}$ & 30 & Transferrine/BMI \\
\hline 7 & $\mathrm{FM}$ kg/BMI & 19 & Albuminemia & 31 & Lynphocythes \\
\hline
\end{tabular}


The Influence of Age on Body Structure and Body Compositionof Patients Undergoing Chronic Peritoneal Dialysis, And Its Relationship with The Treatment Schedules

\begin{tabular}{|c|l|r|l|r|c|} 
& & & \multicolumn{2}{|c|}{ Lynphocythes/B } \\
8 & Extracellular water kgs & 20 & Albuminemia/BMI & 32 & MI \\
\hline 9 & $\begin{array}{l}\text { Extracellular water } \\
\text { kgs/BMI }\end{array}$ & 21 & Cholesterolemia & 33 & C3 \\
\hline 10 & Cellular mass \% & 22 & $\begin{array}{l}\text { Cholesterolemia/B } \\
\text { MI }\end{array}$ & 34 & C3/BMI \\
\hline 11 & Cellular mass \%/BMI & 23 & Triglycerides & 35 & IgG \\
\hline 12 & Cellular mass kgs & 24 & Triglycerides/BMI & 36 & IgG/BMI \\
\hline
\end{tabular}

The following Tables XIII, XIV show the comparison of scores for differences of greater values versus lower values of scores concerning average age versus 60 years age and 67 years age, and of 60 years age versus 67 years age, while Table XV shows the comparison of these differences between males and females

Table XIII - Males - Comparison of scores for differences of greater values versus lower values

\begin{tabular}{|l|l|l|l|}
\hline average age & versus & T value & p value \\
\hline & 60 years & 1.09 & 0.292 \\
\hline & 67 years & 1.14 & 0.271 \\
\hline 60 years & 67 years & 0.22 & 0.827 \\
\hline
\end{tabular}

\begin{tabular}{|c|c|c|c|}
\hline \multirow[t]{3}{*}{ average age } & versus & $\mathrm{T}$ value & $\mathrm{p}$ value \\
\hline & 60 years & 1.73 & 0.144 \\
\hline & 67 years & 2.12 & 0.078 \\
\hline 60 years & 67 years & -0.17 & 0.869 \\
\hline
\end{tabular}

Table XV - Males versus Females- Comparison of scores for differences of greater values versus lower values

\begin{tabular}{|l|l|l|l|}
\hline variables & Versus & T value & $p$ value \\
\hline average age & average age & -2.5 & 0.067 \\
\hline 60 years & 60 years & -1.18 & 0.303 \\
\hline 67 years & 67 years & -2.02 & 0.067
\end{tabular}

Observations onthe Tables I, II, IV, IV A, V, VII, IX, XI, XII and final conclusions

Table I - Males - Differences based on average age - the variables resulting significantly dominant selected by lower age were : height, extracellular water kgs/BMI, cellular mass $\% / \mathrm{BMI}$,cellular mass $\mathrm{kgs} / \mathrm{BMI}, \mathrm{Creatininemia/BMI}$, and dialyzed volume/BMI, while greater age significantly selected age, fat mass \%, fat mass kgs,cholesterolemiaand C3. The variables selected by lower age all concerned physical properties typical of young age, while the variables selected by greater age are usually more enhanced in older subjects. It has to observe that many variables classified as significantly differing in Table I are present also in Table II, which includes variables without significant differences, within them including cellular mass \%, cellular mass $\mathrm{kgs}$, extracellular water \% and extracellular water $\mathrm{kgs}$ that are present in Table I: these variables resulted differ from those in Table I because indexed on BMI, that is proper of each individual.

Tables I, II, II,IV and IV A - In these tables it is possible to note a relevant difference of the data from males and from females, data concerning the differences between the variables separated according to the values greater or lower the average age. These differences resulted in males to be statistically significant in 11 variables and not significant in 11 variables, while in females the significant differences concerned only three variables, age, dialyzed volume and dialyzed volume/BMI, of which age was different for default, and the not significant differences resulted to be 31 (Tables IV and IV A). An elaboration of data concerning males and females was performed to attain an explication of this relevant difference. For this purpose, it was firstly calculated the percentage difference between the greater and lower values of the variables according to greater and lower age. Successively, the calculated percentage was subtracted by the value 100 , this generating positive and negative values, and for this comparison the absolute values of the final percentage differences were assumed, using the formula absolute value $=$ square root of the square value, so that the obtained values could not be defined neither positive or 
negative. The following step was to calculate the mean and the standard deviation of all the percentage differences of the 45 variables, calculated in their wool: It resulted to be for males $17.44 \pm 14.83$ and $3.28 \pm 22.8$ for females, this difference resulting high significant at $\mathrm{T}$ test for two variables, $\mathrm{T}$ value $=$ $-4.19, \mathrm{p}=0.000$, this adequately explaining the very low number of significant differences between greater and lower values for females.

The same procedure was followed about the content of the Tables V, VII, IX, XI, which show the differences greater versus lower of the data concerning 60 years and 67 years. Very different results were obtained: for males, the absolute values concerning the percentage difference greater versus lower for 60 years was 9.35 \pm 31.07 , and for females $64.03 \pm 738.4$, a very great numerical difference, but statistically without significance, $\mathrm{T}$ value $=-0.17, \mathrm{p}=0.877$. It is very relevant to point out that in males the number of significant differences between greater versus lower increased from 11 for average age to 15 differences for 60 years and, similarly for females, the number of significant differences increased from three to five differences, age, extracellular water $\%$, extracellular water kgs. But in the case of 67 years of age, the number of significant differences for males decreased to seven (Table IX), while for females increased to eight. For 67 years, the percentage difference for males resulted $4.9 \pm 161.5$ and for females $57,01 \pm 350,7$, but similarly that for 60 years of age, no significant difference resulted between males and females, $\mathrm{T}$ value $=-0.38, \mathrm{p}=$ 0.714. These results differ from those concerning the different number of variables not having significant difference in males and in females: for what concerning males, for 60 years of age (Table VI) 20 variables, for 67 years (Table X) 38 variables, in females, for 60 years (Table VIII) 30 variables, and for 67 years of age, 36 variables (Table XII), therefore in males and in females the numerousness of not significant differences based on the separation of data greater versus lower age increases with the increase of age. Very different The results concerning the dialytic treatment showed a significant difference in the separation based on average age for males and females, while the separations concerning 60 years and 67 years showed no significant difference for males, but significant difference for females.

Conclusion. These final results seem driving to believe that aging should reduce the differences between greater and lower dimensions of bodily properties: this is indirectly confirmed by the research of Susanne [1], that shown the reduction of body structure with aging, an event also pointed out by Makizaco H. et Al. and by Evans WJ et Al. [2,3]. Fukumoto $\mathrm{Y}$ et Al. pointed out that aging can induce a loss of muscle which may be preceded by a decreased quality of muscle mass [4].

The Tables XIII and XIV show the consequences of absence of differences in the comparisons greater versus lower for what concerning average age versus 60 years and 67 years and of 60 years versus 67 years, this driving to no statistic differences of the related scores, the same for the difference between males and females (Table XV). For what concerning the dialytic treatment, a significant difference was pointed out for males and for females about the average age, but for what concerning the differences greater versus lower of 60 years and 67 years, not significant differences resulted for males, which differently resulted for females, a significant difference was pointed out for males and for females about the average age, but for what concerning the differences greater versus lower of 60 years and 67 years, not significant differences resulted for males, which differently resulted for females, notwithstanding the age should not differ males versus females, as shown in premise.

\section{REFERENCES}

[1] Susanne C. Individual Age Changes of the Morphological Characteristics. Pages 1-9; 27 September 1976.

[2] Makizako H, Shimada H, Doi T, Tsutsumimoto K, Lee S, et Al. Age-dependent changes in physical performance and body composition in community-dwelling Japanese older adults.J Cachexia Sarcopenia Muscle.2017 Aug;8(4):607-614.

[3] Evans WJ, Campbell WW. Sarcopenia and age-related changes in body composition and functional capacity. J Nutr. 1993 Feb;123(2 Suppl):465-8.

[4] Fukumoto Y, Ikezoe T, Yamada Y et Al. Age-Related Ultrasound Changes in Muscle Quantity and Quality in Women. Ultrasound Med Biol 2015: 2003-2007. 